\title{
Implementasi Metoda Sum Squared Error untuk Identifikasi Kategori Pembakaran Mesin Sepeda Motor 4 Tak Bahan Bakar Bensin
}

\section{Sum Square Error Methods Implementation For Combustion Categorizing Identification in 4 Stroke Engine Gasoline Fuel Motorcyle}

\author{
Andrizal ${ }^{1)}$, Rusfandi ${ }^{1)}$ \& Rivanol Chadry ${ }^{2)}$ \\ 1) Jurusan Teknik Elektro Politeknik Negeri Padang Kampus UNAND Limau Manis Padang 25163 \\ Telp 0751-72590 Fax 0752-72576 Email : andrizalpoli@gmail.com, rusfandi74@yahoo.com \\ ${ }^{2)}$ Jurusan Teknik Mesin, Politeknik Negeri Padang Kampus UNAND Limau Manis Padang 25163 \\ Telp 0751-72590 Fax 0752-72576 Email : rivanolchadry@yahoo.com
}

\begin{abstract}
Motorcycles with injection system uses engine scanner tool as a reference for a mechanic when performing a tune-up to find out and get the engine firing conditions were perfect. Unlike the motorcycle carburetor system, relying only on the experience of a mechanic. If using tools, usually using exhaust emission analyzer which only serves to measure the levels of elements and compounds and exhaust emissions and it can not be used to identify the condition of the combustion engine. Besides, not all the workshops have it, just a certain manufacturer authorized workshops, garages and a large scale or related government agencies that have it. There are two categories of combustion engine, the first engine combustion conditions are not perfect and complete combustion conditions. Perfect engine combustion conditions is needed so that maximum engine performance with an efficient use of fuel. This study aims to make a device that is capable of detecting the condition of combustion 4-stroke motorcycle carburetor system using the method of sum square error (SSE) through the value of the data patterns of exhaust emissions based gas sensors. The study, of the five categories of motorcycles with the manufacturer, type and year of manufacture of different shows that, the system made capable of identifying categories of combustion engine based on the SSE on the identification and reference set. The success rate of identification detection system performs the complete combustion of $89.33 \%$ and $97.99 \%$ of incomplete combustion.
\end{abstract}

Keyword: identification, combustion conditions, the pattern data.

\section{PENDAHULUAN}

Setiap penguna kendaraan bermotor menginginkan agar kendaraan yang digunakan efisien dan irit bahan bakar dengan tenaga serta kinerja mesin tetap maksimal. Agar didapat penggunaan bahan bakar yang efisien dan tenaga yang serta performa mesin maksimal diperlukan tindakan-tindakan yang dilakukan oleh tenaga ahli atau sering disebut dengan tune up mesin.

Berdasarkan Badan Pusat Statistik (BPS) pada tahun 2013 terdapat \pm 80 juta pengguna sepeda motor yang terdaftar. Dan dengan pertumbuhan setiap tahun $12 \%$ maka pada tahun 2015 ini diperkirakan 100 juta sepeda motor dengan berbagai tipe dan produsen.
Pengguna sepeda motor secara rutin dan berkala melakukan tune up atau service kendaraan di bengkel sepeda motor. Kegiatan service atau tune up dilakukan oleh tenaga ahli terlatih yang ada pada bengkel-bengkel resmi produsen tertentu atau bengkel-bengkel lainnya yang ada dilingkungan masyarakat. Salah satu kegiatan service rutin yang dilakukan adalah tune up pembakaran mesin yaitu kegiatan service ringan yang dilakukan untuk proses kalibrasi sistem pembakaran mesin. Proses ini meliputi pengaturan pembakaran mesin agar didapat sistem pembakaran mesin yang efisien dan performa dan tenaga yang dihasilkan 
maksimal dengan konsumsi bahan bakar minimal.

Terdapat dua kategori kelompok pembakaran mesin kendaraan bermotor :

1. Pembakaran sempurna

Pembakaran sempurna didapat jika terjadi kesembangan antara bahan bakar yang di hembuskan keruang bakar, udara pembakaran yang dibutuhkan dan sistem pengapian untuk proses pembakaran.

2. Pembakaran tidak sempurna Pembakaran tidak sempurna adalah tidak terdapat keseimbangan ketiga komponen pembakaran yitu bahan bakar, udara dan pengapian. Terlalu kaya diartikan sebagai bahan bakar telalu banyak, sehingga terdapat sejumlah bahan bakar yang tidak terbakar diruang bakar dan ikut terbuang melalui gas buang dengan indikasi gas $\mathrm{HC}$ yang tinggi. Terlalu miskin akibatnya gas buang mengandung unsur dan senyawa gas $\mathrm{CO}$ dan $\mathrm{CO} 2$ yang tinggi sementara tenaga yang dihasilkan minimal.

Kondisi pembakaran sempurna dan tidak sempurna ditentukan oleh komposisi dan kadar unsur dan senyawa gas buang yang ada pada kendaraan ditampilkan seperti pada pada tabel 1 .

Tabel 1. Hubungan unsur dan senyawa gas buang yang dihasilkan dan kondisi pembakaran mesin.

\begin{tabular}{|c|c|c|c|c|}
\hline CO & COt & HC & 02 & Peugatal \\
\hline$\pi$ & L & H & H & Afr ter alu kaya dan pengapian mengalarni inistive \\
\hline $\mathrm{H}$ & L & H & L & $\begin{array}{l}\text { AfF terlalu kaya dan kerusakan pada thermostat a alau coolant } \\
\text { sensor }\end{array}$ \\
\hline L & L & t & H & Kebocoran pada exhaustsystem \\
\hline L & H & L & H & Kegagalan padai injector \\
\hline $\mathrm{H}$ & L & M & H & AfrRterlalukaya \\
\hline H & म & $\mathrm{H}$ & H & 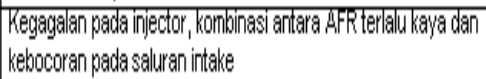 \\
\hline L & L & $\mathrm{H}$ & H & $\begin{array}{l}\text { Kegagalan pada sistern pengapian, AFr terla lu kurus, kebocoran } \\
\text { udara pada saluran artara a airlow sersor dan throttle body. }\end{array}$ \\
\hline & H & & & Kondisiyang tepat \\
\hline
\end{tabular}

Kondisi yang diinginkan adalah $\mathrm{CO}$ low, $\mathrm{CO}_{2}$ High, $\mathrm{HC}$ low dan $\mathrm{O}_{2}$ Low seperti pada tabel 1 .

Keahlian seorang tenaga mekanik saat proses tune up ditunjang oleh pengalaman dan alat bantu yang digunakan.

Terdapat dua jenis sepeda motor yang ada saat ini khususnya di Indonesia jika dilihat dari sistem pengaturan proses pembakaran.

1. Sepeda motor sistem karburator Sepeda motor jenis ini diproduksi umumnya sebelum tahun 2012. Dengan demikian jenis sepeda motor tipe ini masih banyak digunakan oleh masyarakat. Pada sepeda motor jenis ini, pengaturan sistem pengapian, aliran udara, dan injeksi bahan bakar dilakukan secara mekanik.

2. Sepeda motor sistem injeksi (fuel injection).

Jenis sepeda motor ini diproduksi mulai tahun 2010 dan pada tahun 2012 hingga sekarang hampir semua produsen sepeda motor di Indonesia menggunakan sistem injeksi. Sepeda motor sistem ini dilengkapi dengan sistem kontrol elektronik berbasis multi sensor untuk mengontrol injeksi bahan bakar, udara dan sistem pengapian. Disamping itu juga sensor yang ada pada sepeda motor tersebut dapat mendeteksi variable-variable yang dibutuhkan melalui engine scanner unit.

Engine scanner unit merupakan alat bantu bagi tenaga mekanik untuk mendeteksi kondisi pembakaran yang terjadi. Disamping itu alat ini juga dapat digunakan sebagai alat setting point untuk mendapatkan kondisi pembakaran sempurna jika sepeda motor yang diuji terdeteksi pada kondisi pembakaran tidak sempurna. Sehingga dengan adanya alat ini, sangat membantu para mekanik melakukan tune up pembakaran mesin, karena terdapat 
sebuah alat yang dapat dijadikan sebagai data referensi dan uji identifikasi pembakaran mesin.

Sepeda motor sistem karburator tidak dilengkapi dengan sistem kontrol otomatis seperti sistem injeksi. Sehingga untuk proses tune up pembakaran mesin dilakukan secara manual mengandalkan pengalaman dan pengetahuan tenaga mekanik. Misalnya dengan cara mendengarkan bunyi mesin atau irama mesin, melihat asap gas buang, melihat sisa pembakaran pada busi dan kadangkala mencium bau emisi gas buang. Alat bantu yang biasa digunakan berupa alat ukur kadar emisi gas buang dan hasil pengukuran alat ini tidak menunjukkan kategori pembakaran mesin tetapi hanya kadar unsur dan senyawa gas buang yang ada. Untuk menentukan kategori hasil pembakaran diperlukan analisa lebih lanjut, disamping itu alat bantu seperti ini tidak selalu tersedia disetiap bengkel sepeda motor.

Berasarkan prinsip dasar proses pembakaran mesin bahwa hasil pembakaran pada ruang bakar mesin akan menghasilkan kadar unsur dan senyawa dari beberapa gas melalui gas buang dengan nilai tertentu seperti pada tabel 2.

Tabel 2. Standar emisi gas buang untuk sepeda motor sistem karburator bahan bakar bensin pada kondisi pembakaran sempurna.

\begin{tabular}{|l|l|l|}
\hline Jenis Gas & Kadar Gas & Indikator \\
\hline $\mathrm{HC}$ & $200 p p m-400 p p m$ & Low \\
\hline $\mathrm{CO}$ & $1,5 \%-2 \%$ & Low \\
\hline $\mathrm{CO}_{2}$ & $12 \%-15 \%$ & High \\
\hline $\mathrm{O}_{2}$ & $0,5 \%-2 \%$ & Low \\
\hline
\end{tabular}

Dari tabel 2, terlihat hubungan kadar emisi gas buang yang diukur dengan kondisi pembakaran mesin sempurna untuk sepeda motor sistem karburator.

Dengan cara mendeteksi kadar unsur dan senyawa pada gas buang suatu kendaraan dapat digunakan sebagai data untuk menentukan kategori pembakaran mesin. Kadar unsur dan senyawa emisi gas buang ini dapat dideteksi dengan menggunakan sensor yang sensitif terhadap unsur gas dan senyawa $\mathrm{HC}, \mathrm{CO}, \mathrm{CO}_{2}$ dan $\mathrm{O}_{2}$. Hasil deteksi sensor diproses dengan metoda Fast Fourier Transform (FFT) agar ditampilkan data unik pada domain frekuensi. Selanjutnya data hasil FFT ini diproses menjadi data-data unik yang mencirikan kondisi pembakaran mesin sepeda motor. Data-data kondisi pembakaran mesin ini dapat digunakan sebagai data-data referensi dan merupakan data pembanding proses Sum Squared Error (SSE) saat identifikasi pembakaran dilakukan.

Proses indentifikasi dilakukan dengan menghitung jumlah kuadrat selisih data referensi pembakaran dengan data uji yang didapat dengan mengitung nilai SSE sebagai berikut :

$S S E=\sum_{i=0}^{i=n}(x i-y i)^{2}$

Dimana,

SSE adalah jumlah nilai kuadrat error, xi nilai magnitude ke i data referensi, yi nilai magnitde ke i data hasil deteksi.

Keputusan hasil identifikasi untuk menentukan kategori pembakaran mesin apakah pembakaran sempurna atau pembakaran tidak sempurna, ditentukan dengan proses perhitungan nilai SSE.

\section{METODOLOGI}

Metode penelitian yang digunakan pada penelitian ini adalah penelitian eksperimental. Untuk sampel uji adalah sepeda motor 4 tak sistem karburator bahan bakar bensin merek Honda, Yamaha dan Suzuki dengan berbagai tipe dan tahun pembuatan yang berbeda.

Penelitian ini dilakukan untuk membuat sebuah sistem yang mampu digunakan sebagai sistem pengambilan keputusan untuk mendeteksi hasil pembakaran mesin melalui gas buang berdasarkan pola data referensi dan pola data hasil deteksi.

Tahapan yang dilakukan pada penelitian ini adalah 2 tahap berupa tahap persiapan uji dan tahap pelakasanaan uji. 
Tahap Persiapan pengujian :

Tenaga ahli dan peralatan pendukung yaitu teknisi terlatih dari bengkel sepeda motor dan Alat ukur emisi gas buang Exhaust Emission Analyzer yang telah dikalibrasi.

Persiapan bahan uji yaitu sepeda motor yang diuji dalam keadaan baik, tidak mengalami kerusakan mesin dan sistem karburator yang sudah dipastikan oleh tenaga ahli.

\section{Tahap pelaksanaan dan prosedur pengujian :}

1. Proses pengambilan data referensi sebagai data pembanding untuk mendapatkan nilai SSE. Data pembanding ini merupakan data magnitude hasil proses SSE. Proses pengambilan data referensi adalah sebagai berikut :

a. Sepeda motor yang dijadikan sebagai data referensi di tune up pembakaran mesin oleh tenaga mekanik terlatih sehingga didapat kategori pembakaran sempurna.

b. Sepeda motor yang telah di tune up diukur emisi gas buang dengan peralatan Exhaust Emisision Analyzer untuk dianalisa hasil emisi gas buang.

c. Data hasil uji emisi dianalisa dengan acuan pada tabel 2 untuk mendapatkan hasil pembakaran sempurna dan di tune up ulang oleh tenaga mekanik jika diperlukan.

d. Selanjutnya, dipasangkan alat uji untuk mendapatkan pola datakategori pembakaran sempurna.

e. Jika telah didapatkan hasil pola data kategori pembakaran sempurna, maka data ini disimpan sebagai data referensi untuk jenis dan merek sepeda motor.

f. Proses a sampai f diulangi untuk tipe, produsen yang berbeda terhadap beberapa tipe sepeda motor.

2. Proses penentuan nilai maksimum SSE referensi.

Proses uji penentuan batasan nilai SSE dilakuan untuk mendapatkan nilai maksimum SSE yang dijadikan acuan pengambilan keputusan kategori pembakaran dengan cara :

a. Dipilih jenis sepeda motor yang diuji sesuai dengan sepeda motor yang akan diuji.

b. Tentukan nilai SSE random mendekati 0 sebagai nilai SSE referensi untuk nilai awal.

c. Pasang pipa input ruang sensor pada ujung knalpot sepeda motor yang belum ditun up dan amati hasil keputusan identifikasi yang dihasilkan.

d. Analisa hasil keputusan, jika hasil keputusan pembakaran sempurna, turunkan nilai set poin referensi SSE sampai hasil identifikasi tetap pada pembakaran sempurna dan dicatat sebagai nilai referensi SSE.

e. Jika hasil identifikasi pembakaran tidak sempurna, dan lakukan tune up pada sepeda motor oleh tenaga mekanik dan dengan bantuan uji emisi dan analisa hasil uji emisi sampai didapat konsisi pebakaran sempurna.

f. Proses a sampai e diulangi untuk jenis dan merek sepeda motor yang berbeda dan catat sebagai data referensi SSE sesuai dengan jenis sepeda motor.

3. Proses uji identifikasi on line.

Proses uji identifikasi on line ini dilakukan terhadap sepeda motor yang belum di tune up dan tidak diketahui katergori pembakarannya.

a. Pilih jenis sepeda motor dan pilih nilai referensi SSE yang 
sesuai dengan tipe sepeda motor yang diuji.

b. Hidupkan sepeda motor dan tunggu sampai kondisi akselerasi mesin stabil.

c. Pastikan ruang sensor steril dari sisa-sisa gas buang dan sistem sudah dipanaskan, lalu pasangkan pipa input sistem pada ujung knalpot.

d. Tunggu sampai response maksimum dan amati hasil identifikasi.

e. Jika diperlukan lakukan tune up untuk mendapatkan kategori pembakaran sempurna.

f. Lakukan poin a sampai e untuk tipe sepeda motor yang berbeda.

\section{HASIL DAN PEMBAHASAN}

Sistem yang dibuat ini diimplementasikan pada sistem embedded dengan komponen utama modul field Programmable Gate Array (FPGA) pada modul myRIO dari Nasional Instrument.

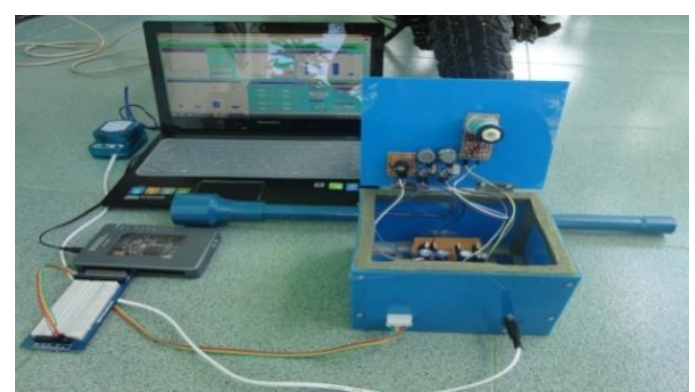

Gambar 1. Bentuk alat secara keseluruhan.

Sistem sensor untuk deteksi gas dibuat parallel, untuk sensor oksigen menggunakan KE 50, MQ 135 untuk sensor CO2, MQ 7 untuk CO dan TGS 2201 untuk HC. Output sensor diperkuat dengan penguat sinyal dan dirubah menjadi besaran digital. Semua proses sistem dilakukan pada modul FPGA, sementara laptop hanya digunakan sebagai media display. Tampilan antara pengguna dengan sistem dibuat sedemikian rupa sehingga memudahkan pengguna memahami hasil proses sistem.

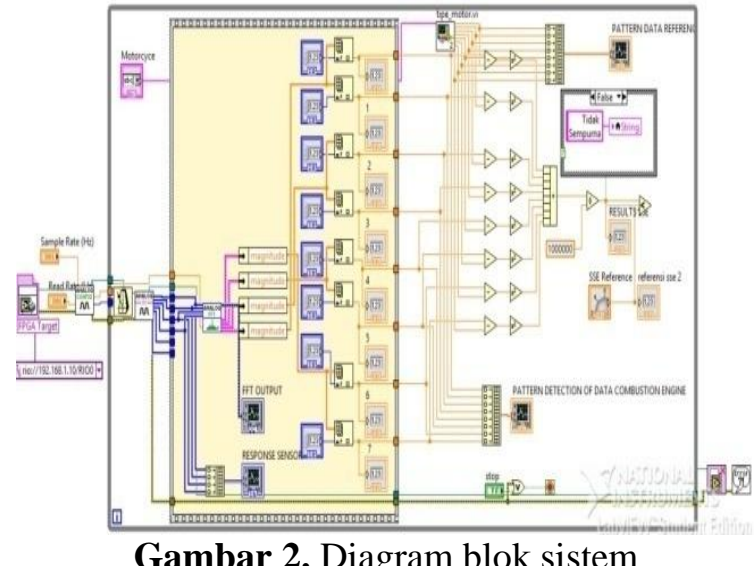

Gambar 2. Diagram blok sistem

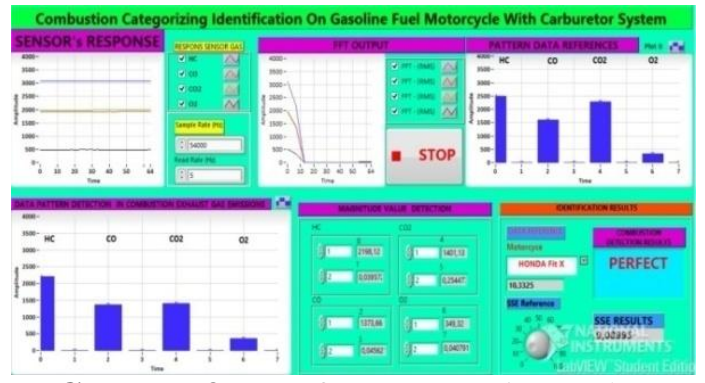

Gambar 3. Interface antara sistem dengan pengguna.

Blok diagram sistem secara keseluruhan atau data flow programming ditampilkan pada gambar 2. Tampilan perantara sistem dengan pengguna ditampilkan pada gambar 3 .

\section{Pengambilan data referensi.}

Proses pengambilan data referensi dilakukan terhadap sejumlah sepeda motor, dengan 30 kali pengamatan untuk masingmasingnya. Dari hasil magnitude 30 kali pengamatan setiap pola data yang didapat, dilakukan perhitungan rata-rata untuk mendapatkan nilai magnitude referensi. Gambar 4 menampilkan hasil perubahan magnitude untuk setiap pola dengan 30 kali pengujian untuk sepeda motor Honda Supra $\mathrm{X}$. Jumlah pola data yang dipilih dari proses SSE adalah sebanyak 8 pola. 


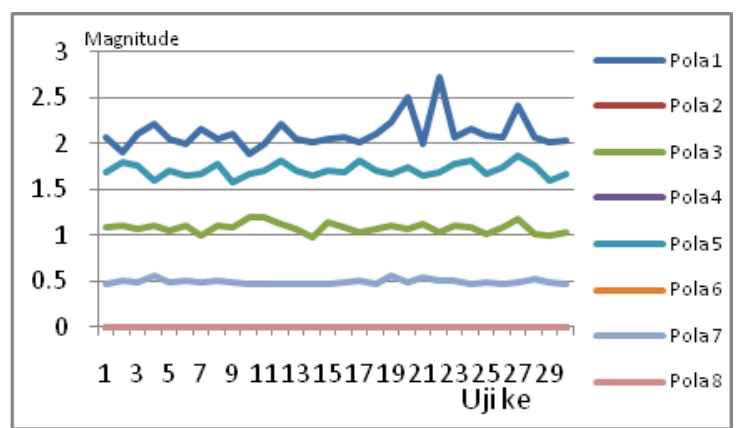

Gambar 4. Perubahan magnitude pola 30 kali pengujian untuk sepeda motor Honda Supra Fit X.

Untuk mendapatkan nilai magnitude yang akan digunakan sebagai nilai referensi maka dihitung nilai rata-rata setiap pola. Hasil akhir untuk pola data referensi Honda Supra Fit X ditunjukkan pada tabel 3.

Tabel 3. Nilai magnitude data referensi sepeda motor Honda Supra Fit X.

\begin{tabular}{|r|r|r|l|r|}
\hline $\begin{array}{c}\text { Pola } \\
\text { Ke }\end{array}$ & Supra X & $\begin{array}{l}\text { Yamaha } \\
\text { Vega }\end{array}$ & $\begin{array}{l}\text { Honda } \\
\text { Revo }\end{array}$ & \multicolumn{1}{l|}{$\begin{array}{l}\text { Suzuki } \\
\text { Shogun }\end{array}$} \\
\hline 1 & 2,10122 & 2,02311 & 2,08276 & 2,1011 \\
\hline 2 & 0,000027 & 0,000017 & 0,000119 & 0,00245 \\
\hline 3 & 1,1872 & 1,1245 & 1,26477 & 1,1977 \\
\hline 4 & 0,000016 & 0,000018 & 0,00013 & 0,000351 \\
\hline 5 & 1,6221 & 1,90021 & 2,00311 & 1,6728 \\
\hline 6 & 0,000017 & 0,000018 & 0,000128 & 0,00127 \\
\hline 7 & 0,37231 & 0,3591 & 0,357219 & 0,38112 \\
\hline 8 & 0,000042 & 0,000041 & $3,11 \mathrm{E}-05$ & 0,00003 \\
\hline
\end{tabular}

Data-data pada tabel 3 digunakan sebagai data referensi untuk menghitung nilai SSE ketika mendeteksi kondisi pembakaran sepeda motor Honda Supra Fit $\mathrm{X}$.

Dengan cara yang sama, seperti yang dilakukan pada sepeda motor Honda Supra Fit $X$, didapatkan nilai magnitude data reerensi untuk beberapa jenis sepeda motor, seperti ditunjukkan tabel 4.

Tabel 4. Magnitude pola data referensi beberapa sepeda motor kategori pembakaran sempurna.

\section{Proses pengaturan nilai SSE referensi}

Nilai referensi SSE dibutuhkan untuk perbandingan ketika sistem melakukan proses pengambilan keputusan kategori pembakaran. Nilai referensi SSE minimum dijadikan sebagai acuan ketika mengambil keputusan kategori pembakaran.

Untuk mendapatkan nilai SSE referensi yang diinginkan dilakukan uji hasil perhitungan nilai SSE antara 2 magnitude pola data hasil deteksi dengan magnitude data referensi. Pertama adalah nilai SSE antara pola data magnitude sepeda motor yang belum di tune up dan diketahui dengan pasti kategori pembakaran tidak sempurna. Nilai SSE kedua adalah hasil perhitungan antara data referensi dengan pola data pembakaran sepeda motor yang telah di tune up dan diketahui pada kategori pembakaran sempurna. Uji pertama dilakukan terhadap sepeda motor Honda Revo dengan bentuk pola data ditampilkan pada gambar 5 .

\begin{tabular}{|c|r|}
\hline $\begin{array}{c}\text { Pola } \\
\text { Ke }\end{array}$ & $\begin{array}{c}\text { Nilai } \\
\text { Magnitude }\end{array}$ \\
\hline 1 & 2.16142 \\
\hline 2 & 0.00066 \\
\hline 3 & 1.12862 \\
\hline 4 & 0.00005 \\
\hline 5 & 1.47706 \\
\hline 6 & 0.00010 \\
\hline 7 & 0.36154 \\
\hline 8 & 0.00007 \\
\hline
\end{tabular}

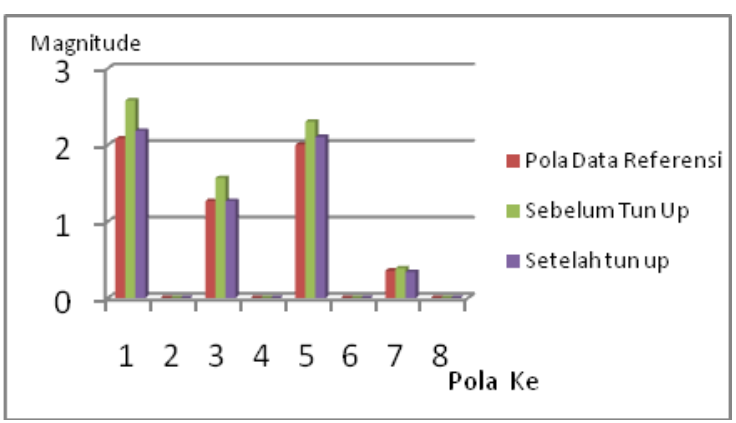

Gambar 5. Pola referensi, sebelum dan setelah tune up Honda Revo. 
Tabel 5. menampilkan hasil uji coba perhitungan nilai SSE untuk 2 pola yang diidentifikasi dengan data referensi.

\begin{tabular}{|c|c|c|c|c|c|}
\hline \multirow[b]{2}{*}{$\begin{array}{c}\text { Pola } \\
\text { Ke }\end{array}$} & \multicolumn{3}{|c|}{ Nilai Magnitude } & \multirow{2}{*}{$\begin{array}{c}(x i-y i)^{2} \\
\text { SSE } 1\end{array}$} & \multirow{2}{*}{$\begin{array}{c}(x i-y i)^{2} \\
\text { SSE } 2\end{array}$} \\
\hline & $\begin{array}{l}\text { Pola Data } \\
\text { Referensi }\end{array}$ & $\begin{array}{c}\text { Sebelum } \\
\text { Tun up }\end{array}$ & $\begin{array}{l}\text { Setelah } \\
\text { tun up }\end{array}$ & & \\
\hline 0 & 2,08276 & 2,58276 & 2,18276 & 0,25 & 0,01 \\
\hline 1 & 0,000119 & 0,000119 & 0,000119 & 0 & 0 \\
\hline 2 & 1,26477 & 1,56477 & 1,26477 & 0,09 & 0 \\
\hline 3 & 0,00013 & 0,00013 & 0,00013 & 0 & 0 \\
\hline 2 & 2,00311 & 2,30311 & 2,10311 & 0,09 & 0,01 \\
\hline 5 & 0,000128 & 0,000128 & 0,000128 & 0 & 0 \\
\hline 6 & 0,357219 & 0,387219 & 0,337219 & 0,0009 & 0,0004 \\
\hline 7 & $3,11 \mathrm{E}-05$ & $3,11 \mathrm{E}-05$ & $3,11 \mathrm{E}-05$ & 0 & 0 \\
\hline \multicolumn{4}{|c|}{ NILAI SSE } & 0,4309 & 0,0204 \\
\hline
\end{tabular}

Tabel 6. Hasil proses penentuan nilai maksimum nilai SSE referensi untuk beberapa tipe sepeda motor.

\begin{tabular}{|l|r|r|r|}
\hline $\begin{array}{l}\text { Jenis } \\
\text { Sepeda } \\
\text { Motor }\end{array}$ & $\begin{array}{l}\text { SSE } \\
\text { Sebelum } \\
\text { Tun Up }\end{array}$ & $\begin{array}{l}\text { SSE } \\
\text { Setelah } \\
\text { Tun Up }\end{array}$ & $\begin{array}{l}\text { SSE Referensi } \\
\text { maksimum yang } \\
\text { ditetapkan }\end{array}$ \\
\hline $\begin{array}{l}\text { Honda } \\
\text { Supra X }\end{array}$ & 0,7201 & 0,0781 & $\mathbf{0 , 1}$ \\
\hline $\begin{array}{l}\text { Honda } \\
\text { Supra Fit X }\end{array}$ & 0,5112 & 0,0324 & $\mathbf{0 , 0 5}$ \\
\hline $\begin{array}{l}\text { Yamaha } \\
\text { Vega }\end{array}$ & 0,6301 & 0,0275 & $\mathbf{0 , 0 5}$ \\
\hline $\begin{array}{l}\text { Suzuki } \\
\text { Shogun }\end{array}$ & 0,5871 & 0,0578 & \\
\hline
\end{tabular}

Dari tabel 5 dapat dilihat bahwa nilai SSE untuk pembakaran tidak sempurna adalah 0,4309 dan nilai SSE untuk pembakaran sempurna adalah 0,0204 setelah dilakukan tune up. Dengan demikian dapat dipilih nilai referensi SSE untuk Honda Revo adalah 0,05. Jika nilai SSE didapat adalah $\leq$ dengan 0,05 pada sistem akan ditampilkan keputusan kategori pembakaran sempurna.

Selanjutnya dengan cara proses yang sama, dilakukan proses perhitungan SSE maksimum terhadap beberapa sepeda motor seperti ditunjukkan pada tabel 6 .

Nilai SSE setelah tune up dijadikan nilai acuan untuk menentukan nilai maksimum SSE yang dijadikan referensi untuk uji coba.

Selanjutnya dilakukan uji coba untuk beberapa sepeda motor dengan kategori pembakaran sempurna dan kategori pembakaran tidak sempurna diamati hasil deteksi pembakaran yang diindentifikasi. uji coba setiap sepeda motor dilakukan sebanyak 30 kali dengan rentang waktu uji coba 10 menit.

Dari hasil uji coba pada tabel 7 , didapatkan hasil identifikasi kategori pembakaran sempurna sebanyak 26 dan kategori pembakaran tidak sempurna 4. Dengan demikian persentasi keberhasilan sistem mendeteksi kategori pembakaran sempurna adalah :

Persentasi keberhasilan deteksi kategori pembakaran sempurna adalah :

$$
\begin{aligned}
\% & =\frac{\text { Total deteksi pembakaransempurna }}{\text { Jumlah uji coba }} \times 100 \% \\
& =\frac{26}{30} \times 100 \% \\
& =0.866667 \times 100 \% \\
& =86,67 \% .
\end{aligned}
$$

Untuk uji coba deteksi kategori pembakaran tidak sempurna dilakukan terhadap sepeda motor Suzuki Shogun. Hasil ujicoba identifikasi ditampilkan pada tabel 8 .

Dari hasil data uji yang didapatkan pada tabel 8, terlihat hasil identifikasi kategori pembakaran tidak sempurna $100 \%$.

Dengan cara uji coba yang sama pada ujicoba deteksi kategori pembakaran sempurna dan kategori pembakaran tidak sempurna, dilakukan terhadap beberapa sepeda motor dengan tipe yang berbeda. Hasil uji coba ini ditunjukan pada tabel 9.

Tabel 7. Hasil uji coba indentifikasi kategori pembakaran sempurna sepeda motor Honda Supra Fit X.

\begin{tabular}{|r|l|l|l|}
\hline $\begin{array}{r}\text { Uji } \\
\text { Ke }\end{array}$ & $\begin{array}{l}\text { SSE } \\
\text { Identifikasi }\end{array}$ & $\begin{array}{l}\text { SSE } \\
\text { Referensi }\end{array}$ & $\begin{array}{l}\text { Hasil } \\
\text { Identifikasi }\end{array}$ \\
\hline 1 & 0.026 & 0.05 & Perfect \\
\hline 2 & 0.048 & 0.05 & Perfect \\
\hline 3 & 0.025 & 0.05 & Perfect \\
\hline 4 & 0.012 & 0.05 & Perfect \\
\hline 5 & 0.034 & 0.05 & Perfect \\
\hline 6 & 0.067 & 0.05 & Not Perfect \\
\hline 7 & 0.032 & 0.05 & Perfect \\
\hline 8 & 0.019 & 0.05 & Perfect \\
\hline 9 & 0.018 & 0.05 & Perfect \\
\hline 10 & 0.029 & 0.05 & Perfect \\
\hline 11 & 0.054 & 0.05 & Not Perfect \\
\hline 12 & 0.056 & 0.05 & Perfect \\
\hline 13 & 0.036 & 0.05 & Perfect \\
\hline 14 & 0.027 & 0.05 & Perfect \\
\hline
\end{tabular}




\begin{tabular}{|l|l|l|l|}
15 & 0.028 & 0.05 & Perfect \\
\hline 16 & 0.012 & 0.05 & Perfect \\
\hline 17 & 0.039 & 0.05 & Perfect \\
\hline 18 & 0.019 & 0.05 & Perfect \\
\hline 19 & 0.041 & 0.05 & Perfect \\
\hline 20 & 0.033 & 0.05 & Perfect \\
\hline 21 & 0.067 & 0.05 & Not Perfect \\
\hline 22 & 0.047 & 0.05 & Perfect \\
\hline 23 & 0.036 & 0.05 & Perfect \\
\hline 24 & 0.027 & 0.05 & Perfect \\
\hline 25 & 0.019 & 0.05 & Perfect \\
\hline 26 & 0.038 & 0.05 & Perfect \\
\hline 27 & 0.047 & 0.05 & Perfect \\
\hline 28 & 0.055 & 0.05 & Not Perfect \\
\hline 29 & 0.042 & 0.05 & Perfect \\
\hline 30 & 0.045 & 0.05 & Perfect \\
\hline
\end{tabular}

Tabel 8. Hasil identifikasi kategori pembakaran tidak sempurna Suzuki Shogun.

\begin{tabular}{|r|l|l|l|}
\hline $\begin{array}{l}\text { Uji } \\
\text { Ke }\end{array}$ & $\begin{array}{l}\text { SSE } \\
\text { Identifikasi }\end{array}$ & $\begin{array}{l}\text { SSE } \\
\text { Referensi }\end{array}$ & $\begin{array}{l}\text { Hasil } \\
\text { Identifikasi }\end{array}$ \\
\hline 1 & 0.68 & 0.08 & Not Perfect \\
\hline 2 & 0.58 & 0.08 & Not Perfect \\
\hline 3 & 0.78 & 0.08 & Not Perfect \\
\hline 4 & 0.89 & 0.08 & Not Perfect \\
\hline 5 & 0.54 & 0.08 & Not Perfect \\
\hline 6 & 0.57 & 0.08 & Not Perfect \\
\hline 7 & 0.92 & 0.08 & Not Perfect \\
\hline 8 & 0.94 & 0.08 & Not Perfect \\
\hline 9 & 0.28 & 0.08 & Not Perfect \\
\hline 10 & 0.52 & 0.08 & Not Perfect \\
\hline 11 & 0.71 & 0.08 & Not Perfect \\
\hline 12 & 0.56 & 0.08 & Not Perfect \\
\hline 13 & 0.51 & 0.08 & Not Perfect \\
\hline 14 & 0.29 & 0.08 & Not Perfect \\
\hline 15 & 0.43 & 0.08 & Not Perfect \\
\hline 16 & 0.69 & 0.08 & Not Perfect \\
\hline 17 & 0.77 & 0.08 & Not Perfect \\
\hline 18 & 0.56 & 0.08 & Not Perfect \\
\hline 19 & 0.44 & 0.08 & Not Perfect \\
\hline 20 & 0.81 & 0.08 & Not Perfect \\
\hline 21 & 0.54 & 0.08 & Not Perfect \\
\hline 22 & 0.65 & 0.08 & Not Perfect \\
\hline 23 & 0.34 & 0.08 & Not Perfect \\
\hline 24 & 0.81 & 0.08 & Not Perfect \\
\hline 25 & 0.48 & 0.08 & Not Perfect \\
\hline 26 & 0.22 & 0.08 & Not Perfect \\
\hline 27 & 0.31 & 0.08 & Not Perfect \\
\hline & & & \\
\hline
\end{tabular}

\begin{tabular}{|l|l|l|l|}
28 & 0.54 & 0.08 & Not Perfect \\
\hline 29 & 0.41 & 0.08 & Not Perfect \\
\hline 30 & 0.57 & 0.08 & Not Perfect \\
\hline
\end{tabular}

Berdasarkan pada tabel 7 , tabel 8 dan tabel 9, maka keberhasilan deteksi untuk kategori pembakaran sempurna dengan SSE referensi adalah $=\frac{86,67+93.33+90+83.33+93.33}{5}=$ $89.33 \%$.

Sedangkan untuk deteksi kategori pembakaran tidak sempurna adalah $\%=\frac{100+96.67+93.3+100+100}{5}=97.99 \%$.

Berdasarkan data uji dan persentasi kemampuan deteksi sistem, maka SSE referensi yang digunakan untuk setiap sepeda motor megakibatkan sistem mampu mendeteksi kategori pembakaran sempurna $89.33 \%$ dan $97.99 \%$ untuk kategori pembakaran tidak sempurna.

Tabel 9. Hasil uji deteksi kategori pembakaran sempurna dan kategori pembakaran tidak sempurna berdasarkan SSE referensi pada tabel 6 untuk beberapa jenis sepeda motor.

\begin{tabular}{|l|c|c|}
\hline \multirow{2}{*}{$\begin{array}{c}\text { Sepeda } \\
\text { motor }\end{array}$} & \multicolumn{2}{|c|}{ \% Hasil identifikasi } \\
\cline { 2 - 3 } & $\begin{array}{l}\text { Pembakaran } \\
\text { sempurna }\end{array}$ & $\begin{array}{l}\text { Pembakaran tidak } \\
\text { sempurna }\end{array}$ \\
\hline Honda Revo & 93.33 & 96.67 \\
\hline $\begin{array}{l}\text { Honda } \\
\text { Supra Fit X }\end{array}$ & 90 & 93.3 \\
\hline $\begin{array}{l}\text { Honda } \\
\text { Supra X }\end{array}$ & 83.33 & 100 \\
\hline $\begin{array}{l}\text { Yamaha } \\
\text { Vega }\end{array}$ & 93.33 & 100 \\
\hline
\end{tabular}

\section{Uji identifikasi on line}

Uji on line dimaksudkan untuk mengetahui kemampuan sistem mengidentifikasi kategori pembakaran sepeda motor yang belum diketahui kategori pembakarannya. jika teridentifikasi kategori pembakaran sempurna, maka proses dihentikan, tetapi jika terdeteksi kategori pembakaran tidak sempurna, Selanjutnya teknisi melakukan tun up bersamaan dengan dteksi sistem sampi didapat hasil deteksi kategori pembakaran sempurna. hasil uji coba ini ditampilkan pada tabel 9 . 
Tabel 10. hasil identifikasi sistem sebelum dan setelah tun up untuk sepeda motor Yamaha Vega.

\begin{tabular}{|c|l|l|l|l|l|}
\hline Pola Ke & $\begin{array}{c}\text { Magnitude } \\
\text { Referensi }\end{array}$ & $\begin{array}{c}\text { Sebelum } \\
\text { Tun Up }\end{array}$ & \multicolumn{1}{|c|}{ (xi-yi) $^{\mathbf{2}}$} & $\begin{array}{c}\text { Setelah } \\
\text { Tun Up }\end{array}$ & (xi-yi) $^{\mathbf{2}}$ \\
\hline 1 & 2,023110 & 2,300400 & 0,07689 & 2,021420 & $2,85 \mathrm{E}-06$ \\
\hline 2 & 0,000017 & 0,000770 & $5,610 \mathrm{E}-07$ & 0,000502 & $2,352 \mathrm{E}-07$ \\
\hline 3 & 1,124500 & 1,504200 & 0,144172 & 1,116320 & $6,691 \mathrm{E}-05$ \\
\hline 4 & 0,000018 & 0,000053 & $1,225 \mathrm{E}-09$ & 0,000034 & $2,56 \mathrm{E}-10$ \\
\hline 5 & 1,900210 & 1,567590 & 0,1106364 & 1,707230 & 0,037241 \\
\hline 6 & 0,000018 & 0,000094 & $5,776 \mathrm{E}-09$ & 0,000215 & $3,885 \mathrm{E}-08$ \\
\hline 7 & 0,359100 & 0,365877 & $4,592 \mathrm{E}-05$ & 0,358234 & $7,497 \mathrm{E}-07$ \\
\hline 8 & 0,000041 & 0,000013 & $7,84 \mathrm{E}-10$ & 0,000020 & $4,41 \mathrm{E}-10$ \\
\hline \multicolumn{7}{|c|}{ Nilai SSE } & $\mathbf{0 , 3 3 1 7}$ & Nilai SSE & $\mathbf{0 , 0 3 7 3}$ \\
\hline \multicolumn{7}{|c|}{ Hasil Identifikasi } & P,05 \\
\hline
\end{tabular}

Selanjutnya dengan cara yang sama didapat hasil identifikasi terhadap beberapa sepeda motor, seperti ditampikan pada tabel 11.

Tabel 11. hasil identifikasi kategori pembakaran beberapa jenis sepeda motor.

\begin{tabular}{|l|c|c|c|c|c|}
\hline \multirow{2}{*}{ Sepeda motor } & \multirow{2}{*}{$\begin{array}{c}\text { Referensi } \\
\text { SSE }\end{array}$} & \multicolumn{4}{|c|}{ Hasil Deteksi } \\
\cline { 3 - 6 } & & Sebelum Tun Up & \multicolumn{2}{|c|}{ Setelah Tun Up } \\
\cline { 3 - 6 } & SSE & Identifikasi & SSE & Identifikasi \\
\hline Honda Revo & 0.05 & 0.27 & $\begin{array}{c}\text { Not } \\
\text { Perfect }\end{array}$ & $\mathbf{0 . 0 3 3}$ & Perfect \\
\hline $\begin{array}{l}\text { Honda Supra Fit } \\
\text { X }\end{array}$ & 0.05 & 0.15 & $\begin{array}{c}\text { Not } \\
\text { Perfect }\end{array}$ & $\mathbf{0 . 0 4 1}$ & Perfect \\
\hline Honda Supra X & 0.1 & 0.68 & $\begin{array}{c}\text { Not } \\
\text { Perfect }\end{array}$ & $\mathbf{0 . 0 7 8}$ & Perfect \\
\hline Suzuki Shogun & 0.08 & 0.38 & $\begin{array}{c}\text { Not } \\
\text { Perfect }\end{array}$ & $\mathbf{0 . 0 5 7}$ & Perfect \\
\hline
\end{tabular}

Dari tabel 10 dan tabel 11 dapat dianalisa bahwa sebelum tune up nilai SSE identifikasi lebih tinggi diatas nilai referensi SSE. Nilai SSE sebelum tune up lebih besar dari 0,1 sedangkan nilai SSE setelah tune up kurang dari 0,1. Jadi untuk deteksi sepeda motor ini, referensi SSE maksimum dapat digunakan 0,1 .

\section{SIMPULAN}

Berdasarkan hasil ujicoba dan analisa hasil, maka dapat disimpulkan sebagai berikut :

1. Jumlah data referensi yang digunakan dan data identifikasi sebanyak 8 data yang mewakili pola data kadar emisi kategori pembakaran.

2. Pola data kategori pembakaran sempurna yang digunakan sebagai data referensi memiliki nilai magnitude tertinggi 2,161 dan terendah 0.00007 .
3. Nilai referensi SSE digunakan sebagai batasan maksimum untuk pengambilan keputusan saat identifikasi kategori pembakaran.

4. Tingkat keberhasilan sistem mengidentifikasi kategori pembakaran sempurna 89,33 \% dan kategori pembakaran tidak sempurna $97,99 \%$.

5. Nilai SSE hasil deteksi pembakaran tidak sempurna besar dari 0,1 dan untuk pembakaran sempurna kurang dari 0,1. Jadi referensi SSE maksimum dapat digunakan untuk sistem ini adalah 0,1 .

\section{SARAN}

1. Untuk mendapatkan data referensi yang valid pada kategori pembakaran sempurna, sebaiknya saat tune up dilakukan oleh beberapa orang tenaga mekanik yang sudah teruji keahliannya.

2. Sebaiknya pada saat pengujian dipastikan ruang sensor steril dari sisa gas buang sebelumnya dengan manambahkan exhaust fan.

\section{UCAPAN TERIMA KASIH}

Terima kasih kepada Dirjen Dikti dan Politeknik Negeri Padang yang telah mendanai kegiatan penelitian ini melalui dana penelitian BOPTN Politeknik Negeri Padang dengan no. kontrak 076 / PL9. 1.4 / LT/2015. 


\section{DAFTAR PUSTAKA}

Bakeri Mustafa, Syarief A, Kusairi Ach.," Analisa gas buang mesin berteknologi EFI dengan bahan bakar premium", INFO TEKNIK, Volume 13 No. 1, Juli 2012.

Eka N.J, Hakam Mohamad, S. Indri," emisi gas carbon monooksida (co) dan hidrocarbon (hc) pada rekayasajumlah blade turbo ventilator sepeda motor "supra $\quad$ 125 tahun 2006," Volume $\quad 16$ No 2 Tahun 2014, Jurnal Rotasi Jurusan Teknik Mesin, Politeknik Perkapalan Negeri Surabaya.

EPA. Environmental Protection Agency, "Engine Test Cells/Stands NESHAP.” 28 Aug. 2003.

Honda Technical Service Sub Division. (1991).: Pengantar Teori Motor Bakar Bensin. Jakarta : Astra Honda Training Center, PT. Astra International, Inc.

Isnanda,"Pengaruh Gas Buang Terhadap Kinerja Motor Bensin", Volume 4 No 2 tahun 2007, Jurnal Teknik Mesin, Politeknik Negeri Padang.

Jayanti, N.E., (2013).,Pengaruh Perubahan Jumlah Blade Supercharger Pada Sepeda Motor Mesin Empat Langkah Terhadap Emisi Gas Buang (CO Dan HC).Politeknik Perkapalan Negeri Surabaya. Surabaya.

Kusuma, W.I.GB. (2002), "Alat Penurun Emisi Gas Buang pada Motor, Mobil, Motor Tempel dan Mesin Pembakaran Tak Bergerak", Program Studi Teknik Mesin. Universitas Udayana, Kampus Bukit Jimbaran, Bali.

Kementrian Negara Lingkungan Hidup,"Ambang batas emisi gas buang kendaraan bermotor lama"
Peraturan Menteri Negara

Lingkuangan no 5 tahun 2006.

National instruments application notes," Testing Automotive Exhaust Emissions, ".tahun 2013.

Novyanto, Okasatria. Tanpa Tahun. Mengenal Motor Bakar.

Rupali V. Chothe, Sunita P. Ugale," ENose for gas detection at vehicle exhaust Using supervised learning algorithm" Volume 1, Issue 4, IJETTS page 145-149, 2012.

Setya B.N, S.Pd.T,"Aplikasi Teknologi Injeksi Bahan Bakar Elektronik (EFI) Untuk Mengurangi Emisi Gas Buang Sepeda Motor", Volume 2 No 5 Nofember 2007, D3 Teknik Mesin Universitas Negeri Semarang.

Sigit P.H dan Jamyamah Siti," Alat uji emisi gas buang kendaraan bermotor", Jurnal penelitian vol 7 hal 5-10, BAPPEDA Jogyakarta, April 2012.

Sutiman, "Upaya Pengendalian Pencemaran Udara Melalui Pengembangan Teknologi Motor Bensin dan EMS", Universitas Negeri Yogyakarta.2004.

Van, Basshuysen Richard, and Fred Schäfer. Internal Combustion Engine Handbook: Basics, Components, Systems, and Perspectives.Warrendale, PA: SAE International, 2004.

Victor V. Kosegeran, Elia Kendekallo, MSc, Sherwin R. U. A. Sompie, ST., MT, Bahrun, MKes, " Perancangan Alat Ukur Kadar Karbon Monoksida (CO), Karbon Dioksida (CO2) dan Hidro Karbon (HC) Pada Gas Buang Kendaraan Bermotor", e-Journal Teknik Elektro dan Komputer, Jurusan Teknik Elektro, UNSRAT, Tahun 2013. 